\title{
Paraplegia
}

\section{The Use of a Calcium Alginate Dressing in the Management of Decubitus Ulcers in Patients with Spinal Cord Lesions}

\author{
A. Chapuis, MD, P. Dollfus, MD \\ Centre de Readaptation, 57 rue Albert Camus, 68093 Mulhouse Cedex, France.
}

Calcium alginate $\left(\text { Sorbsan }{ }^{\circledR}\right)^{\star}$ has been used as a haemostatic dressing for many years. It has also been used in the treatment of leg ulcers and other types of wounds (Gilchrist and Martin, 1983; Odugbesan and Barnett, 1987).

We have used it in a clinical trial for more than 2 years (1986-1987) in the management of pressure sores in patients with spinal cord lesions including 3 patients with other neurological involvements.

\section{Materials and methods}

The dressing

Alginates are natural polysaccharides found only in the brown seaweeds available along the West coast of Scotland. The Sorbsan ${ }^{\circledR}$ dressing is made from the calcium salt of alginic acid prepared as a high quality textile fibre and presented for use as either a woolly or a flat non-woven pad. It is sterile and contained in a doublewrapped peel pack. The dressing can be applied for all patients on whom normal wound dressings are used. It offers the additional advantage of a high absorption of fluids by a hydrophilic gel formation. Sorbsan ${ }^{\circledR}$ is soluble in normal saline sodium bicarbonate or sodium citrate solutions at normal physiological concentrations.

Our protocol for the use of Sorbsan ${ }^{\circledR}$

Application (only after the sore has been completely excised and deterged):

1. The wounds were cleaned with sterile saline solution.

2. The Sorbsan ${ }^{\circledR}$ dressing was applied directly to the wounds.

3. The dressings were covered by the usual gauze dressings and fixed by skin tapes.

* Sorbsan ${ }^{\circledR}$ is manufactured by Steriseal Ltd, UK. 
4. A sterile saline solution was used to remove the dressings as well as to clean the wound.

The dressings were performed twice a day for the first 3 days, once a day for the 3 following days, and thereafter 2 or 3 times a week depending on the quantity of fluids absorbed.

\section{Patients}

Thirty pressure sores were treated with the alginate fibre dressing on 19 patients: 15 males and 4 females. One patient had 4 sores, 2 patients had 3 sores, 4 patients had 2 sores and 12 patients only 1 sore. The average age of the patients was 39 years (from 20 to 69 ).

\section{Lesions}

10 paraplegic patients: 6 complete and 4 incomplete.

6 tetraplegic patients: 4 complete and 2 incomplete.

1 patient with multiple sclerosis.

1 patient with a 'locked-in syndrome'.

1 patient with a sacral tumour, involving the sacral peripheral nerves.

\section{Sore location}

$\begin{array}{lr}\text { Sacral } & 9 \\ \text { Ischiatic } & 12 \\ \text { Trochanteric } & 3 \\ \text { Maleolar } & 1 \\ \text { Heels } & 4 \\ \text { Perineal } & 1\end{array}$

Depth of the sores (Guttmann's classification, 1973)

Stage 2 of permanent damage to cutaneous tissues: 11 .

Stage 3 of deep penetrating necrosis: 19.

All the sores were productive in the beginning. Most of them were necrotic and 17 showed an extensive undermining of the skin.

\section{Results}

Healing was completed and of good quality after continuous use of Sorbsan ${ }^{\circledR}$ in 21 sores $(66 \%)$. Three sores healed very rapidly. Thereafter the treatment had to be changed to a superficial wound dressing (Vaseline gauze). Six sores were operated on (3 trochanteric and 3 ischiatic). All the sores which were operated on belonged to the third stage and had a large extensive zone of undermining of the skin. One failure is reported because of a severe local pseudomona anginosa infection after 11 days of treatment. 
No pain was reported in patients with incomplete lesions, or in those with normal sensation. No allergic reactions were reported.

\section{Duration of treatment with Sorbsan ${ }^{\circledR}$}

Treatment lasted for a total of 1694 days with an average treatment of 56.4 days (minimum 11; maximum 190 days). The average duration was 28.9 days for stage 2 sores and 72.4 days for those with deep penetrating necrosis.

\section{Discussion}

The use of Sorbsan ${ }^{\circledR}$ dressings appears to have given good clinical results in the treatment of pressure sores in patients with spinal cord lesions. The advantages of Sorbsan ${ }^{\circledR}$ appeared to be:

1. The high absorption of the exudate.

2. An effective odour remission which is a desirable result of its high absorptive capacity.

3. Easy removal of adherent dressings by use of saline which facilitates the change from the insoluble calcium salt to a readily soluble sodium alginate.

4 Conformability: the dressing readily adapts itself to fill the wound cavity and to match irregular contours of the sore.

The cost/efficiency ratio is difficult to evaluate because of multiple individual and biological factors. Our clinical impression (and that of the nursing staff), is that the dressings were less time-consuming. The cost of the dressing per se is compensated for by the reduced frequency of use. A similar comparative trial has been performed in another centre (Schwartz, 1986). It confirmed our impression that the overall length of stay in hospital, because of the sore(s) only, was less than with traditional dressings.

\section{References}

GILCHRIST T, MARTIN AM 1983 Wound treatment with Sorbsan - an alginate fiber dressing. Biomaterials 4:317-320.

GuttmanN L 1973 Spinal Cord Injuries. Comprehensive Management and Research. Blackwell Scientific Publications, London, pp 518-534.

ODUGBESAN O, BARNETT AH 1987 Use of a seaweed-based dressing in management of leg ulcers in diabetics: a case report. Practical Diabetes 4:46-47.

SCHWARTZ JL 1986 Personnal communication. 